\title{
Is Moral Bioenhancement Dangerous?
}

\author{
Nicholas Drake \\ Australian National University \\ nicholas.drake@anu.edu.au
}

Penultimate draft of paper published in Journal of Medical Ethics, 42 (1):3-6. 2016.

\section{Introduction}

In Unfit for the Future Persson and Savulescu describe the inadequacies in normal moral judgement (Persson and Savulescu 2012). Normal moral judgement fails to deal with certain major problems, they claim, because it involves a bias towards outcomes in the near future, an indifference to the suffering of great numbers, a bias against the relevance of omissions relative to acts, and a bias against collective contributions to harm. Persson and Savulescu suggest that avoiding catastrophes such as climate change and nuclear war requires the extensive application of moral education to address the deficits of normal moral judgement and to inculcate "norms that are conducive to the good of the world community" (Persson and Savulescu 2012: 123). However, they believe that extensive moral education might not be sufficient to avert disaster. They suggest that given the seriousness of the situation the possibility of moral bioenhancement should also be considered.

In an interesting response to Persson and Savulescu, "Moral Bioenhancement is Dangerous," Nicholas Agar (2015) argues that moral bioenhancement is dangerous as it will almost certainly result in mistaken moral judgements. Agar holds that normal moral judgement should be "privileged" because it involves the application of various moral subcapacities in a balanced way. He argues that moral bioenhancement would increase moral subcapacities in an unbalanced way and that, as a result, mistaken moral judgements are likely to occur. He concludes that moral bioenhancement is dangerous, and does so with 
a high degree of certainty: morally worse outcomes are "almost inevitable." I will argue that Agar gives insufficient justification for this conclusion.

In the section "Clarifying the argument," I discuss an ambiguity in Agar's view of normal moral judgement and give my reasons for treating moral subcapacity balance as the basis of his argument. I then argue that Agar's thesis that moral bioenhancement is likely to result in incorrect moral judgements fails in two ways. First, in the section "A false trichotomy," I argue against Agar's assertion that a higher than normal level of a particular moral subcapacity is dangerous. I suggest that Agar employs a false trichotomy in implying that moral subcapacities are categorised as deficient, normal and excessive. I argue that levels of particular subcapacities can be higher than normal without being excessive, and that these higher levels can be desirable; and that there is not sufficient reason to think that moral bioenhancement is likely to leapfrog desirable higher levels and arrive at excessive levels. ${ }^{1}$ Second, in the section "Against normal moral judgement," I argue that there is good reason for thinking that Persson and Savulescu are right and Agar wrong about the likelihood of normal moral judgement being correct. If normal moral judgement is not as likely to be correct as Agar thinks, his thesis that non-normal moral judgements resulting

${ }^{1}$ Psychologists speak of capacities as having "levels." A capacity is the potential to accomplish a particular task. Take, for example, Simon Baron-Cohen's definition of empathy as the ability to recognise and respond appropriately to the thoughts and feelings of others (Baron-Cohen 2011). We can say then that a person can have more or less ability than normal to recognise and respond appropriately to the thoughts and feelings of others, can thus have "more" or "less" empathy than normal and can be said to have a "high level" or "low level" of empathy. Likewise, if the capacity of moral reasoning is the ability to understand moral arguments and reach reasoned conclusions, a person may have more or less ability to do this than normal, and thus may have a "high level" or "low level" of the capacity for moral reasoning. We can thus speak of people with the lowest or highest relative levels of a moral subcapacity as having an "extremely low level" or "extremely high level" of that subcapacity. I use the term "extreme" on its own in this paper to refer to extremely high levels of subcapacities, so that, for example, "extreme empathy" refers to an extremely high level of empathy. 
from moral bioenhancement would be dangerous is weakened. I conclude that Agar does not give sufficient reason to think that moral bioenhancement is dangerous. I will not, however, argue that moral bioenhancement is safe, desirable or necessary.

\section{Clarifying the argument}

Persson and Savulescu hold that normal moral judgement is problematic because it involves systematic biases which mean that it fails to sufficiently respond to possible catastrophes such as anthropogenic climate change or nuclear war. Agar holds in contrast that moral normalcy should be "privileged," and morally normal people are "reference points." "They are reference points not because they are necessarily morally correct... But they possess the cognitive, emotional and motivational capacities required to grasp moral arguments and to implement their conclusions."

Agar's argument involves some ambiguity, as his reason for privileging normal moral judgement, that it involves the capacities required to understand and implement moral arguments, implies that the morally bioenhanced will lack those capacities. However, in all of Agar's examples of dangerous moral judgements he believes the morally bioenhanced are likely to arrive at, the morally bioenhanced do have at least normal levels of those capacities. In the case of morally bioenhanced persons he believes likely to become terrorists, Agar states that they have exceptional ability to understand and implement moral arguments; it is precisely that exceptional ability that Agar says is dangerous in that case. It seems then that the danger of moral bioenhancement is not that the morally bioenhanced will be unable to understand moral arguments and implement their conclusions.

At the conclusion of his paper Agar states that "It is the bypassing of reason that makes moral bioenhancement so unlikely to succeed." This implies that the problem with 
moral bioenhancement is that improvements in a person's moral judgement are dangerous unless they are the result of her reasoning about moral questions. On this interpretation of Agar's position, normal moral judgement is often incorrect, but is more likely to be correct than bioenhanced moral judgement as the latter improves moral capacities by non-rational means: the empathy, reasoning and commitment of the morally bioenhanced are likely to result in incorrect moral judgements as they have not been developed through the application of reason.

Although I feel this may be the most charitable interpretation of Agar's view, and it has the virtue of avoiding the contradiction between his view that the morally normal are reference points because they have the ability to understand and implement moral arguments and his examples of dangerous morally bioenhanced persons who nevertheless also have at least normal levels of that ability, it remains problematic. This is because the substance of Agar's argument does not deal with the issue of whether moral bioenhancement will bypass reason. The substance of Agar's argument is instead that the moral judgement of morally bioenhanced persons is far more likely to be incorrect than the moral judgements of normal persons as normal people have balanced moral subcapacities and the morally bioenhanced are likely to have imbalanced moral subcapacities. I will therefore focus not on the issue of moral bioenhancement bypassing reason but on the issue of subcapacity balance.

\section{A false trichotomy}

Agar argues that correct moral judgements are the result of a balance of moral subcapacities. He does not specify these, but his paper includes mention of broad empathy (empathy for a wide range of persons or beings), deep empathy (strong empathy for a 
narrow range of persons or beings with whom one is familiar), reasoning and moral commitment (the ability to act on one's moral judgements).

Agar argues that in normal people it is the relative levels of a person's moral subcapacities, not the absolute levels, which determine the quality of his or her moral judgement. So whereas the moral judgement of a psychopath may benefit from an increase in empathy to a normal level, the moral judgement of a person with a normal level of empathy will get worse with an increase in empathy: "with respect to moral subcapacities, excesses are as bad as deficiencies." 2 The suggestion is that an increase in a particular moral subcapacity above normal levels is likely to result in a morally extreme person such as, in Agar's examples, someone who would burglarise a hospital or allow hundreds of millions of deaths. ${ }^{3} \mathrm{~A}$ flaw in this argument is that it considers only three possible types of moral judgement: moral judgement that is wrong because of deficient moral subcapacities, such as that of psychopaths; normal moral judgement; and extreme moral judgement, such as, again in Agar's examples, that of terrorists or of doctors who carry out painful experiments on their children. There is, though, no obvious reason why it is not possible that there are also people who are morally exceptional, in the good sense, in particular ways. As the category

${ }^{2}$ An increase is not the same as an excess, but Agar's argument implies that any increases in moral subcapacities above normal levels would be excessive. Otherwise he would not have his stated need for concern; he could accept moral bioenhancement that increased moral subcapacities to nonexcessive levels.

${ }^{3}$ Another interpretation of Agar's argument might be that it holds not that increases in normal levels of subcapacities will result in extreme levels of those subcapacities, but instead that as extreme levels in a particular subcapacity are bad any increase in a particular subcapacity is also bad. But that would be a non-sequitur, so I believe the most charitable interpretation to be the one I employ. 
of moral excellence is excluded from Agar's considerations he is unlikely to arrive at a reliable prediction of the effects of changes in individuals' moral subcapacities.

Psychologists tell us that capacities such as empathy, moral motivation and moral reasoning do not exist on the three levels of deficient, normal and excessive, but on spectra. For example, empathy "is truly a continuum, a seamless dimension" (Baron-Cohen 2011: 202 n. iv) and moral reasoning is also assessed on a continuum (Stepien and Baernstein 2006). This means that moral bioenhancement to increase a normal person's particular moral subcapacity need not cause him or her to have an excessive level of that subcapacity. Normal levels of empathy are the middle range of a bell curve (Baron-Cohen 2011: 18); this means that an increase in the empathy of a morally normal person can result in him or her having a level of empathy still well within the normal range. Thus, there is no obvious reason why increases in empathy through bioenhancement would be likely to cause normal people to have levels of empathy at the far right of the bell curve.

There seem to be many people with higher than normal levels of particular moral subcapacities who do not have bad moral judgement. For example, some people have high levels of empathy relative to their other subcapacities; they tend to help others in need more than most people do and to support organisations that work to reduce suffering, such as animal rights, medical or development charities. ${ }^{4}$ Some people have high levels of moral commitment relative to their other subcapacities; whereas other people might believe that there are major moral problems that need to be addressed but do nothing about them, those with high moral commitment take action to address those problems. Some people have high

4 This is not to imply that the reverse is true, namely, that if a person works to reduce suffering they must do it due to high levels of empathy, and this is true, mutatis mutandis, of the examples of other high subcapacities that follow. 
levels of the capacity for moral reasoning in relation to their other subcapacities; they include many of those who argued against racism, sexism and homophobia when those positions were the moral norm. It seems reasonable to think that having all moral subcapacities to a high degree is better than having one or two to a high degree, but it is not obvious that having one or two moral subcapacities to a high degree causes incorrect moral judgements, and it seems in most cases to just involve having strengths in particular moral areas. If so, there is nothing to fear from the bioenhancement of moral subcapacities to the level of morally exceptional people, even where those people have particular moral strengths. Further, a person with a pluralistic disposition will appreciate the variety of contributions to the moral sphere that variation in moral subcapacity balance creates.

Take for example Baron-Cohen's example of a person who has what he calls "superempathy," Archbishop Desmond Tutu. He tells of Tutu struggling not to cry out loud when listening to victims' testimony at the Truth and Reconciliation Hearings, which he chaired, and of his empathy extending towards white guards and officers, who Tutu recognized "deserved dignity and the opportunity to show remorse" and "experience forgiveness" (Baron-Cohen 2011: 187-188). The "super-empathy" of Desmond Tutu involves no dangerous moral judgement; rather, it seems to facilitate exceptional moral judgement. Baron-Cohen regards extreme empathy as "wholly positive" in its effects on others. To give another real-world example, empathy training for medical professionals, who we can presume tend to be morally normal, "is believed to significantly influence patient satisfaction, adherence to medical recommendations, clinical outcomes, and professional satisfaction" (Stepien and Baernstein 2006). These effects indicate improvements, not worsenings, in moral judgement. 
Another indication that raising levels of empathy in normal people is not dangerous is the significant difference in average levels of empathy between men and women. This difference is well established (Toussaint and Webb 2005), and a study by Willer, Wimer and Owens (2015) attributes to it the lower rates of charitable giving by men. This illustrates three points. Firstly, it shows that there is not a single level or narrow band of normality for the moral subcapacity of empathy, as average empathy is significantly higher among women than men. Secondly, it shows that the enhancement of a moral subcapacity in a person with a normal level of that subcapacity need not cause an abnormal level of that subcapacity: a person with the average level of empathy for a man who has that level enhanced might then have the average level of empathy for a woman. Thirdly, it indicates that increasing particular moral subcapacities does not result in mistaken moral judgements. Presumably, women do not have worse moral judgement than men, and presumably, there is nothing faulty in women's judgement that they should give at least the amount to charity that they do. In that case, it is reasonable to think that increasing the empathy of the average man will not result in worse moral judgements and will instead result in arguably better moral judgements, such as the judgement that they should give to charity at least the greater amount that women do. Now, there may not be the technical means to bioenhance empathy in this way; but the issue is not whether it is possible, but whether or not, if it were possible, it would be likely to result in mistaken moral judgements. And unless women's higher level of giving to charity is mistaken, or women have worse moral judgement in general than men do, such bioenhancement is not likely to result in mistaken moral judgements.

Thus Agar's view that raising normal levels of a moral subcapacity is likely to result in incorrect moral judgements is undermined by the facts that moral subcapacities exist on 
continua, not the three discrete levels of deficient, normal, and excessive; that having strength in a particular moral subcapacity can be beneficial, not harmful, for moral judgement; and by the empathy gap between men and women, which indicates that increasing the level of empathy in normal men to that of normal women would likewise not be harmful, and might be beneficial.

\section{Against normal moral judgement}

Agar fails to give sufficient reason to support the idea, contra Persson and Savulescu, that normal moral judgement is more likely to be correct than non-normal moral judgement. If normal moral judgement is not as likely to be correct as Agar implies, we have less reason to think that bioenhanced moral judgements are dangerous.

Whereas Persson and Savulescu argue for the possible desirability of moral bioenhancement on the basis that normal moral judgment is dangerously flawed, Agar relies on normal moral judgement as a "reference point," and appeals to "strongly felt moral intuitions" in support of moral normalcy. This is in danger of begging the question: the argument that non-normal moral intuitions are dangerously unreliable cannot easily be defended by appeal to normal moral intuitions without circularity. Persson and Savulescu take a consequentialist approach to moral questions, evaluating moral judgements by whether they cause benefit or harm; thus in the following discussion I will leave aside discussion of the epistemic status of moral intuition, for which there is not space here, and instead discuss whether normal moral judgements are more likely than bioenhanced judgements to cause benefit and avoid harm, broadly speaking. This seems compatible with Agar's approach, as causing more harm than good is a reasonable interpretation of what he means by moral bioenhancement being "dangerous." 
Agar's confidence in moral normalcy is illustrated in his discussion of his first hypothetical example of unbalanced moral subcapacities:

Case A: A mother breaks into a hospital, steals a dialysis machine, and sells it on eBay to provide her child with a higher quality of education.

Agar states that the mother has made an incorrect moral judgement as a result of giving excessive weight to the second of two moral ideas:

Moral Idea One: Beings with a similar capacity to benefit and suffer harm deserve similar treatment.

Moral Idea Two: Parents should give special consideration to their children. Agar suggests that moral normalcy involves a balance between the two ideas, and that the incorrect moral judgement of the mother results from her unusual weighting of Moral Idea Two and could occur in morally bioenhanced persons as "a possible result of the enhancement of the moral subcapacity of empathy."

It is not obvious that moral normalcy and strongly felt intuitions do have the balance of Moral Idea One and Moral Idea Two at the right level, if our measure is harmful and beneficial consequences. Consider the following case:

Case X: It costs $\$ 14.21$ to inoculate a child in sub-Saharan Africa from polio, diphtheria, pertussis, tuberculosis, and measles: painful, debilitating, and potentially fatal illnesses (Jamison et al. 2006). A parent has $\$ 160,000$ and a child who is accepted into both MIT's and Pennsylvania State University's four-year programmes. MIT costs $\$ 40,000$ per year. Penn State costs $\$ 30,000$ per year. The parent can use the full $\$ 160,000$ to pay for her child to attend the number five ranked MIT or send her to the number sixty-one ranked Penn State and use the saving of $\$ 40,000$ to save 2815 
children from possible pain, disability and death. She spends the $\$ 40,000$ on a marginal improvement in her child's education and lets the 2815 children take their chances.

This is normal moral judgement: decisions like this happen countless times every day. Currently more than 30 million children are unimmunised from easily preventable diseases, and nearly 30,000 children under five die each day from preventable causes (UNICEF).

Normal moral judgement places so much weight on Moral Idea Two relative to Moral Idea One that it already supports actions far more harmful than those in Case A, on a massive scale. In Case A, a single hospital may be hit with higher insurance costs. If there happens to be no other dialysis machine available the health and possibly life of a very small number of people may be affected. In Case X, of the 2815 impoverished children not protected from polio, diphtheria, whooping cough, tetanus, tuberculosis and measles, many are likely to suffer death or permanent disability. It is precisely because normal moral judgement is so often harmful that Persson \& Savulescu advocate moral education and consider the possibility of moral bioenhancement. One might object that consequentialist moral judgements of the kind I have used here are wrong; but we cannot hold that they are wrong and normal moral intuitions right on the basis of normal moral intuition without begging the question in favour of moral normalcy.

Most importantly, there is no reason to think that any increase in weight given to Moral Idea One - beings with a similar capacity to benefit and suffer harm deserve similar treatment - must cause worse moral judgements, rather than a justified increase in concern 
for strangers. Thus, there is no reason to think that any such increase caused by bioenhancement would be dangerous rather than beneficial.

The argument Agar gives is that moral normalcy has the right balance, and that a change in that balance will likely result in dangerous moral judgements. Both premises are unconvincing: it is not obviously right for parents to prefer marginal increases in their own children's wellbeing over massive increases in the wellbeing of a great number of other children to the extent that they do, and it is likely that parents can give some greater weight to the wellbeing of others' children without making incorrect moral judgements. Thus there is some higher level of empathy for others such that moral bioenhancement to that level is not dangerous.

\section{Conclusion}

Although Persson and Savulescu consider the possibility of effective moral bioenhancement unlikely at present and possibly for the future, they suggest that given the grave consequences of continuing with the status quo the possibility of moral bioenhancement should not be dismissed without serious consideration. Agar's argument that moral bioenhancement is likely to act by increasing particular moral subcapacities to dangerous levels is an interesting response. However, it fails in two ways. Firstly, in considering only three levels of moral subcapacities - deficient, normal, and excessive Agar presents a false trichotomy, as he omits consideration of the category of exceptional moral judgement. His argument requires that increases in particular moral subcapacities from normal levels will leapfrog desirable higher levels and arrive at extreme levels, but gives insufficient reason to think this is likely. In fact, people commonly have varying levels of particular moral subcapacities without having poor moral judgement or extreme moral 
views, and often with beneficial effects. Secondly, Agar does not justify the view that moral normalcy involves the right balance of moral subcapacities, and thus does not justify the view that morally bioenhanced judgements are likely to be incorrect. It may be that moral bioenhancement is dangerous; but Agar's argument fails to justify that thesis. ${ }^{5}$

${ }^{5} \mathrm{I}$ 'm grateful to Jacinta Cording, Richard Joyce, and an anonymous referee for their comments on previous drafts of this paper. 


\section{References}

Agar, Nicholas. 2015. "Moral Bioenhancement is Dangerous." Journal of Medical Ethics 41 (4):343-345.

Baron-Cohen, Simon. 2011. The Science of Evil: On Empathy and the Origins of Cruelty. New York: Basic Books.

Jamison, Dean T., Joel G. Breman, Anthony R. Measham, George Alleyne, Mariam Claeson, David B. Evans, Prabhat Jha, Anne Mills, and Philip Musgrove, eds. 2006. Disease Control Priorities in Developing Countries. 2nd ed. New York, NY: Oxford University Press.

Persson, Ingmar, and Julian Savulescu. 2012. Unfit for the Future: The Need for Moral Enhancement. Oxford: Oxford University Press.

Stepien, Kathy A., and Amy Baernstein. 2006. "Educating for Empathy." Journal of General Internal Medicine 21 (5):524-30.

Toussaint, Loren, and Jon R. Webb. 2005. "Gender Differences In the Relationship Between Empathy and Forgiveness." The Journal of Social Psychology 145 (6):673-685.

UNICEF. "Why Are Children Dying?".

\section{http://www.unicef.org/immunization/index why.html.}

Willer, Robb, Christopher Wimer, and Lindsay A. Owens. 2015. "What Drives the Gender Gap in Charitable Giving? Lower Empathy Leads Men to Give Less to Poverty Relief." Social Science Research 52:83-98. 